\title{
Produtividade do trabalho e mudança estrutural nas indústrias brasileiras extrativa e de transformação, 1970-2001
}

FREDERICO ROCHA*

Work productivity and structural change in Brazilian mining and manufacturing industries. Using an indicator of labor productivity, this paper aims to assess the contribution of structural changes in the Brazilian manufacturing and mining industries to productivity growth, during the 1970-2001 period. The conclusion is that: (i) there is no evidence to sustain that the Brazilian industry has definitely reversed the productivity growth rates slowdown trend; (ii) there is no clear evidence of a positive influence of the structural bonus; and (iii) job creation seems to be concentrated in low productivity growth sectors.

Key-words: productivity; manufacturing and mining industries; structural change

JEL: O12; O14; L60

\section{INTRODUÇÃO}

O objetivo deste trabalho é mensurar a contribuição da mudança estrutural para o incremento da produtividade da indústria extrativa e de transformação no Brasil (doravante denominada puramente de indústria), no período de 1970 a 2001. A partir de indicadores setoriais da produtividade do trabalho, o artigo usa uma análise shift-share para avaliar a relação entre crescimento da produtividade e processos de transformação estrutural em distintas fases do desenvolvimento brasileiro que o período abrange.

\footnotetext{
"Professor Adjunto do Instituto de Economia da UFRJ. Endereço: Instituto de Economia - UFRJ, Av. Pasteur, 250, Praia Vermelha — Rio de Janeiro. (E-mail: fred@ie.ufrj.br). O autor agradece o apoio da FAPERJ e do PIBIC-CNPq. A elaboração deste trabalho desfrutou de discussões e comentários de David Kupfer e Fábio Freitas e da contribuição de dois pareceristas anônimos. O trabalho não poderia ser realizado sem as tabulações e o manuseio de bases de dados realizados por Daniela Pires e Flávia Tenório. Desnecessário afirmar que os erros e omissões presentes são de inteira responsabilidade do autor. Submetido: julho 2005; Aceito: fevereiro 2006.
} 
Chenery (1986) separa as visões do crescimento econômico em duas principais correntes. De um lado, estão os tradicionais modelos de crescimento, preocupados com as condições de equilíbrio de longo prazo para o crescimento do PIB. Hipótese comum "desses" modelos é a inexistência de obstáculos para movimentos de recursos de um setor para outro, implicando em produtividade marginal semelhante entre os distintos setores da economia. Nessa abordagem, a explicação do crescimento da renda per capita de um país está centrada no incremento da relação capital-trabalho e na avaliação do resíduo de Solow, que aparece como uma medida da redução do custo real de produção da economia (Harberger, 1998). A tentativa de explicar sua evolução segue duas trajetórias. Por um lado, economistas procuram explicar o incremento na produtividade mediante teorias do capital humano e, por outro, o foco da análise se volta para o progresso tecnológico, culminando em modelos que procuram endogeneizar o progresso técnico. A principal crítica a esse tipo de abordagem está relacionada à dificuldade de captar os desequilíbrios surgidos em processos de desenvolvimento. Conforme ressaltado por Chenery (1986), a hipótese de livre mobilidade de recursos, principalmente em economias em desenvolvimento que apresentam algumas peculiaridades no que se refere ao mercado de fatores, está longe de simular adequadamente o funcionamento da economia.

O segundo tipo de abordagem está centrado na relevância da transformação estrutural, ou seja, na composição setorial da demanda e da produção. Nesse último contexto, o processo de desenvolvimento seria resultado de mudança de recursos de segmentos de menor produtividade para segmentos de maior produtividade, o que aceleraria o processo de crescimento (Chenery, 1986). Na metáfora utilizada por Harberger (1998), o crescimento da economia tomaria mais a forma de cogumelo que brota de um dia para o outro com expansões em distintas direções do que um processo de fermentação, que corresponderia a um crescimento uniforme de todas as suas dimensões. Nesse sentido, o crescimento da produtividade da economia não seria simplesmente resultado de incremento na qualidade dos recursos, como supõem as teorias do capital humano, ou aumento do esforço tecnológico, como sugerem os formuladores de teorias do crescimento endógeno, mas uma série de elementos que envolvem, entre outras coisas, economias de escala e movimentos intersetoriais e inter-empresariais de recursos.

Este último elemento deve ser particularmente relevante para o estudo da economia brasileira, que passou por profundas reformas institucionais de cunho liberalizante, cujo objetivo envolvia a realocação de recursos entre setores a mudança na relação capital-trabalho, na direção de técnicas mais intensivas em mãode-obra, fator abundante (Reinhardt e Peres, 2000).

A seção 1 trata da literatura sobre a mudança estrutural, procurando traçar hipóteses para o comportamento da estrutura industrial em processos de desenvolvimento. A seção 2 apresenta a base de dados utilizada no artigo. Na seção 3 são apresentados os principais resultados empíricos do trabalho. 


\section{ANTECEDENTES ANALÍTICOS: TRANSFORMAÇÃO ESTRUTURAL}

\subsection{Bônus Estrutural}

A discussão sobre a influência do processo de mudança estrutural no crescimento da produtividade está centrada na análise de países em desenvolvimento. O processo de desenvolvimento é compreendido como "um conjunto de processos de transformações estruturais de longo prazo que acompanham o crescimento" (Syrquin, 1988:205). Existem muitas acepções para estrutura e muitos são seus usos em economia. O sentido utilizado neste trabalho se refere à tradição de Kusnetz (1973), de composição setorial do emprego. Por conseguinte, transformação estrutural implica mudanças na localização setorial do fator trabalho ou dos fatores de produção de uma forma geral. A aceleração do crescimento em países em desenvolvimento teria como principais determinantes um aumento na taxa de investimento e a aceleração da produtividade dos fatores de produção. Esse último elemento estaria principalmente associado à realocação dos recursos para setores de maior produtividade. $\mathrm{O}$ incremento da produtividade fruto desses movimentos é conhecido na literatura como "bônus estrutural."

Além dos deslocamentos de fatores dos setores de baixa produtividade para segmentos de alta produtividade, existem outros elementos influenciando a ocorrência do bônus estrutural. Harberger (1998) enfatiza que a contribuição de cada setor para o crescimento da produtividade é bastante distinta e, principalmente, tende a permanecer diferente por um longo período de tempo. Portanto, além de um elemento estático, existe um importante elemento dinâmico na contribuição de cada setor para o crescimento da produtividade. Dentro desse raciocínio, a dinâmica da especialização produtiva pode ter efeitos sobre o crescimento da produtividade. Países que se especializam em setores de alto crescimento da produtividade tendem a ter taxas de crescimento superiores àquelas apresentadas por países especializados em segmentos de baixo crescimento da produtividade. Isso só não ocorreria se o progresso técnico fosse repassado para os preços $(\mathrm{Fa}$ gerberg, 2000). A dinâmica da especialização produtiva surge, assim, como um dos determinantes do bônus estrutural. Esse aspecto é particularmente relevante quando se verifica que uma das principais diferenças entre os períodos a serem analisados neste trabalho é o grau de abertura comercial que influencia fortemente a especialização da economia.

Uma importante característica das abordagens originais sobre mudança estrutural é o foco nos grandes setores. Assim, o bônus estrutural estaria muito mais associado à transferência de recursos da agricultura para a indústria (Syrquin 1988). Pouca ênfase é dada, nos primeiros trabalhos, às mudanças ocorridas dentro da indústria de transformação. Recentemente, Timmer e Szirmai (2000) levantam algumas formas tomadas pela transferência de fatores entre setores que podem gerar incremento da produtividade. Uma das formas de transferência geradoras de bônus estrutural seria o movimento de recursos de indústrias leves com baixa relação capital-trabalho - para indústrias pesadas com alta relação 
capital-trabalho. Uma outra forma seria a transferência de indústrias tradicionais para indústrias nascentes, normalmente associadas a uma maior produtividade.

Enquanto a evidência empírica sobre o bônus estrutural nas mudanças de fatores da agricultura para a indústria parece bastante forte (Syrquin, 1988), em movimentos internos à indústria, ela não assume a mesma clareza. Salter (1960) encontra resultados bastante fortes em favor do bônus estrutural com dados referentes ao Reino Unido no período de 1924 a 1950. Contudo, trabalhos recentes apontam para a neutralidade do bônus estrutural ou até mesmo para o efeito negativo da mudança estrutural sobre o crescimento da produtividade (Fagerberg, 2000; e Timmer e Szirmai, 2000). ${ }^{1}$

Carvalheiro (2003) faz uma análise dos impactos provenientes da mudança estrutural sobre a produtividade, medida pela razão entre valor adicionado e emprego, para a economia brasileira como um todo, no período de 1990 a 2000. Sua análise sugere que, enquanto o aumento da produção e a redução do emprego contribuíram para o crescimento da produtividade, as mudanças estruturais do emprego tiveram o efeito inverso.

A principal razão apontada por Fagerberg (2000) para essa diferença é a relação entre setores tecnologicamente dinâmicos e emprego. No período analisado por Salter (1960), o incremento de $1 \%$ na taxa de crescimento da produtividade implicava um incremento de $1,4 \%$ do emprego, enquanto no período analisado por Fagerberg (2000), essa relação cai para $1 \%$ e para menos de $0,5 \%$ respectivamente. Ao mesmo tempo, ao contrário do que ocorre no período até 1950, os setores mais dinâmicos perdem participação no emprego entre 1970 e 1990. As indústrias de alto crescimento da produtividade não parecem, portanto, grandes geradoras de emprego.

\subsection{Evolução da Produtividade da Indústria no Brasil}

Bonelli (2002) aponta uma tendência histórica de decréscimo da produtividade da indústria no Brasil que teria sido interrompida na década de 90, provavelmente por um processo de mudança institucional, representado principalmente pela abertura comercial da economia. Assim, no imediato pós-guerra, a produtividade da indústria, que crescia a uma taxa anual de pouco menos de $6 \%$, foi reduzida para cerca de $3 \%$ na década de 60 e $2,5 \%$ na década de 70 , chegando a taxas negativas na década de 80 . Contudo, a partir do início da década de 90, a indústria apresenta taxas anuais de crescimento da produtividade bastante elevadas (7,19\% entre 1990 e 1995 e 8,31\% entre 1995 e 2000$)$.

Existem duas interpretações distintas sobre o impacto da abertura comercial sobre a produtividade. De um lado, estão aqueles que acreditam que a abertura

\footnotetext{
${ }^{1}$ A análise de Fagerberg (2000) cobre cerca de 30 países no período de 1973 a 1990, enquanto Timmer e Szirmai (2000) se referem a quatro países asiáticos em desenvolvimento no período de 1973 a 1993.
} 
comercial representou um deslocamento do eixo dinâmico da indústria brasileira em direção ao exterior (Ferreira e Rossi, 2003; Muendler, 2002; e Schor, 2003) e uma mudança definitiva na trajetória de crescimento da produtividade. ${ }^{2}$ Para esses autores, a abertura vem a incrementar a produtividade mediante dois mecanismos:

1. A possibilidade de importação de máquinas, equipamentos e insumos que permite o uso de técnicas mais modernas, ${ }^{3}$ assim como a redução dos custos e do uso de componentes mais eficientes;

2. Processo competitivo - a abertura comercial teria, nesse caso, propiciado um ambiente mais seletivo, fazendo eliminar técnicas e empresas menos eficientes.

A segunda interpretação vem daqueles que sugerem certo ceticismo quanto ao fôlego da retomada do crescimento da produtividade nos anos 90 (Ferraz, Kupfer e Iootty, 2004; Kupfer, 2004). Esses autores atribuem o crescimento da produtividade a uma forte redução do emprego, concentrada nas empresas líderes, que enfatizaram duas estratégias: a substituição de máquinas e equipamentos obsoletos e a desverticalização, externando certas etapas de produção e aumentando a taxa de importação de componentes. Principalmente no caso da compra de bens e equipamentos, esses autores identificam uma concentração de importação em meados da década de 90 , com posterior redução, fruto principalmente de mudanças nos preços relativos. Nesse sentido, sugerem haver pouco fôlego quanto à continuidade do crescimento da produtividade. Levantam ainda a possibilidade de estar havendo, na condução do eixo dinâmico da economia para o setor externo, um processo de especialização industrial regressiva, ${ }^{4}$ ou seja, especialização em segmentos pouco avançados tecnologicamente. O ponto central nessa discussão está voltado para a capacidade de o país crescer especializando-se em indústrias de baixo conteúdo tecnológico.

Este trabalho apresenta algumas contribuições para essa discussão. Em primeiro lugar, ao focar na evolução da produtividade, o trabalho se abstém da discussão sobre a intensidade tecnológica dos setores. ${ }^{5}$ Em segundo lugar, ao elaborar uma análise shift-share da evolução da produtividade, visando captar a influência da mudança estrutural, o trabalho propicia uma medida da contribuição dinâmica de especialização para o crescimento da produtividade. Em terceiro lugar, ao abordar em um longo período de tempo, possibilita a visão de distintos momentos, permitindo identificar um ponto de inflexão.

\footnotetext{
${ }^{2}$ Esses autores medem produtividade pela produtividade total dos fatores.

${ }^{3}$ Conforme a Pesquisa Industrial de Inovação Tecnológica do IBGE (PINTEC) mostra, o investimento em máquinas e equipamentos é a principal fonte de esforço inovador da indústria.

${ }^{4}$ Termo cunhado por Coutinho (1997).

${ }^{5}$ Não que este autor não a considere relevante.
} 


\section{DESCRIÇÃO DE DADOS E METODOLOGIA}

\subsection{Medindo o Bônus Estrutural}

Indicadores de produtividade são classificados de acordo com o uso de um ou mais fatores de produção e de acordo com a mensuração do produto, se baseados em uma medida de valor bruto da produção ou de valor adicionado. Este artigo utiliza a produtividade aparente do trabalho medida pela razão entre o valor adicionado e o pessoal ocupado na indústria, ${ }^{6}$ em 31/12 de cada ano da análise. $\mathrm{O}$ uso de indicadores dessa família para medir a produtividade setorial apresenta virtudes e limitações cuja avaliação extensa ultrapassa os objetivos deste artigo. Recomenda-se a leitura do Manual da OCDE (2001) para uma excelente resenha sobre o assunto.

Na mesma linha de Fagerberg (2000) e Timmer e Szirmai (2000), uma análise shift-share é utilizada para mensurar o efeito da mudança estrutural sobre o emprego. A taxa de crescimento da produtividade será definida por $g=\frac{P^{t}-P^{t-1}}{P^{t-1}}$, em que $P$ é a produtividade e $g$ a taxa de crescimento da produtividade. A produtividade no período inicial será definida como $P^{t-1}=\sum_{i=l}^{n} P^{t-1} s_{i}^{t-1}$, em que $\frac{E_{i}}{E}$ é a participação do emprego do setor $i$ no emprego total e $P_{i}^{t-1}$, a produtividade do setor $i$. Portanto, $\frac{\sum P_{i}^{t-1} s_{i}^{t}-\sum P_{i}^{t-1} s_{i}^{t-1}}{\sum P_{i}^{t-1} s_{i}^{t-1}}$. Fica claro que dois fatores intervêm no aumento da produtividade. De um lado, a produtividade intra-setorial pode estar variando; de outro, pode haver variação da distribuição inter-setorial do emprego.

Assim, pode-se expressar o crescimento da produtividade por:

(1) $(1+g) P^{t-1}=\left[\begin{array}{l}\left(1+g_{1}^{p}\right)\left(1+g_{1}^{s}\right) P_{1}^{t-1} s_{1}^{t-1}+\left(1+g_{2}^{p}\right)\left(1+g_{2}^{s}\right) P_{2}^{t-1} s_{2}^{t-1}+\ldots \\ +\left(1+g_{n}^{p}\right)\left(1+g_{n}^{s}\right) P_{n}^{t-1} s_{n}^{t-1}\end{array}\right]$

em que $g_{i}^{\mathrm{p}}$ é a taxa de crescimento da produtividade do setor $i$, e $g_{i}^{\mathrm{s}}$ é a taxa de crescimento da parcela do emprego do setor $i$. A partir de (1), pode-se, após algumas manipulações algébricas, obter:

(2)

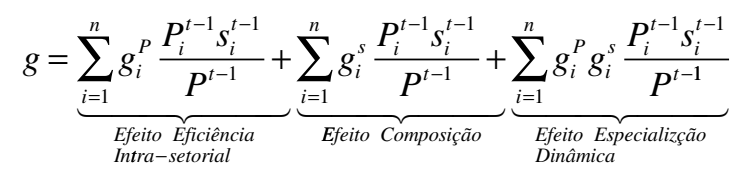

\footnotetext{
${ }^{6}$ A utilização de pessoal ocupado apresenta deficiência, uma vez que a utilização do fator trabalho na indústria pode apresentar variações, mantendo-se constante o pessoal ocupado mediante alterações do número de horas trabalhadas. Contudo, esse dado não é captado pelas pesquisas industriais usadas. Deve ainda ser ressaltado que este trabalho utiliza o pessoal ocupado total no setor, não discriminando se diretamente envolvido na produção ou não.
} 
Em uma economia sem mudança estrutural, ou seja, sem alteração na participação do fator trabalho de cada setor no total do trabalho da indústria, o termo do efeito composição será 0 e o termo do efeito especialização dinâmica também será 0 . Logo, a única causa do crescimento da produtividade terá sido intra-setorial, de mudança na eficiência das empresas. Caso a composição do emprego tenha se alterado e a produtividade de cada setor tenha se mantido constante, a variação da produtividade terá sido conseqüência pura do efeito composição. Isso pode ocorrer, por exemplo, quando as indústrias de alta produtividade contratam mais do que as indústrias de baixa produtividade, ainda que nenhuma delas tenha alterado sua produtividade individualmente. Tenta-se aqui captar os dois efeitos em conjunto. Quando tanto a produtividade intra-setorial quanto a composição intersetorial do emprego se alteram, um terceiro efeito deve ser mensurado referente à interação do efeito eficiência intra-setorial e do efeito composição estrutural. Suponha a existência de dois setores com a mesma participação inicial na produtividade. O primeiro setor tem alta taxa de crescimento da produtividade e o segundo setor tem baixa taxa de crescimento da produtividade. Se há incremento da participação do segmento de alto crescimento da produtividade no emprego, o terceiro termo da equação (2) será positivo. Caso contrário, será negativo. No caso de $n$ setores, para uma dada ponderação inicial $\frac{P_{i}^{t-1} s_{i}^{t-1}}{P^{t-1}}$,
se os setores de maior incremento da produtividade aumentarem sua participação no emprego em detrimento dos setores de menor crescimento da produtividade, o terceiro termo da equação será positivo. Nesse sentido, ele resume a direção da especialização da economia ou, como definem Timmer e Szirmai (2000), o efeito composição dinâmico.

\subsection{Base de Dados}

O trabalho foca no incremento da produtividade entre os anos de 1970, 1980, 1985, 1996 e 2001. A escolha da periodização tenta compatibilizar diferentes estágios da economia brasileira com a disponibilidade de dados. ${ }^{7}$ Informações para 1970, 1980 e 1985, são extraídas dos Censos Industriais do IBGE para os respectivos anos. Dados de 1996 e 2001 advêm da Pesquisa Industrial Anual (PIA) do IBGE. Como proxy do valor adicionado, utiliza-se o valor da transformação industrial que resulta da diferença entre o valor bruto da produção e os custos das operações industriais. Os valores foram transformados a preços constantes de agosto de 1994 pelo Índice de Preços no Atacado (IPA) setorial da FGV. ${ }^{8}$

Foram feitas duas importantes adaptações para compatibilizar os dados da PIA com o Censo Industrial. Primeiro, foi necessário adequar a Classificação Na-

\footnotetext{
${ }^{7}$ Os Censos Industriais se encontram à disposição nos períodos analisados. A PIA de 1990 apresenta problemas associados à expansão de sua amostra e encontra elevadas dificuldades para conversar com a PIA de anos posteriores.
}

${ }^{8}$ Ver anexo 1 para a tabela de conversão da classificação setorial. 
cional de Atividades Econômicas (CNAE) da PIA à classificação utilizada pelo Censo Industrial. A tabela de conversão é apresentada no anexo 1. Permanecem alguns problemas associados à localização dos serviços de manutenção e reparação, centralizados na CNAE e distribuídos pelos setores usuários no Censo. Em segundo lugar, o Censo Industrial utiliza o conceito de estabelecimento do IBGE para a coleta de dados, enquanto a PIA coleta dados no nível da unidade local. Essa diferença cria algumas distorções que devem ser explicitadas. O conceito de estabelecimento do IBGE permite a divisão de uma mesma unidade local em diferentes estabelecimentos, de acordo com a heterogeneidade dos produtos. Dessa maneira, uma unidade local produtora de equipamentos que também produza aço, no primeiro caso, aparecerá dividida em dois estabelecimentos.

\section{RESULTADOS}

\subsection{Evolução da Indústria}

A indústria brasileira apresentou elevado grau de instabilidade no período de 1970 a 2001. Em média, o valor bruto da produção cresceu 4,5\% a.a., no período analisado. No mesmo período, o valor adicionado se incrementou 4,35\% a.a., e o pessoal ocupado, 2,53\% a.a., resultando em um crescimento médio da produtividade de cerca de $1,77 \%$ a.a. (0). Percebe-se, contudo, que há grandes flutuações nos sub-períodos expostos. Entre 1970 e 1980, tanto o valor da transformação industrial quanto o pessoal ocupado crescem, resultando em um incremento da produtividade de 1,81\% a.a. Já entre 1980 e 1985, há contração no valor adicionado, mas também elevação do pessoal ocupado, implicando diminuição da produtividade. O período de 1985 a 1996 apresenta elevação do valor da transformação industrial com redução do pessoal ocupado, resultando na maior taxa de crescimento da produtividade de todo o período. Esse período coincide com a implantação do processo de abertura comercial, que teve início no final da década de 80 , e com a estabilização dos preços a partir de 1994. Entre 1996 e 2001, há uma desaceleração do crescimento do valor da transformação industrial e o pessoal ocupado volta a crescer, obtendo-se um incremento da produtividade bastante reduzido.

Os dados apresentados coincidem com Bonelli (2002), ${ }^{9}$ que levanta evidência de queda do crescimento da produtividade entre o imediato pós-guerra e o final da década de 80 . Segundo o autor, a taxa de crescimento da produtividade da indústria se situava próximo a $6 \%$ ao ano na década de 50 , tendo mantido uma tendência de queda até atingir cerca de $2,5 \%$ na década de 70 , e obtendo taxas negativas durante a década de 80 . A partir de 90 , há uma mudança nessa

${ }^{9}$ Bonelli (2002) utiliza a medida de produtividade física do trabalho. 
tendência, quando a economia passou a registrar taxas de crescimento da produtividade recordes, superiores a $7 \%$ ao ano. A maior discordância entre os dados de Bonelli (2002) e os apresentados neste trabalho está relacionada ao período de 1996 a 2001, em que a produtividade, de acordo com os dados mencionados, cresce a uma taxa inferior a $0,5 \%$ a.a. e, pelos dados de Bonelli, se incrementa a taxas próximas a $8 \%$. Existem importantes razões para essas diferenças:

1. O próprio Bonelli (2002) chama a atenção para a possibilidade de haver super-estimativa do crescimento da produtividade pela utilização de séries de produção física (PIM-pf), em vez de valor adicionado no período de 1990 a 2000, principalmente na segunda metade da década, quando parte substantiva da produção das empresas foi externada e houve forte incremento da parcela de consumo intermediário advinda do exterior; e

2. A PIA apresenta um espectro de tamanho de empresas mais amplo do que a PIM-pf e uma atualização da composição setorial mais adequada. Este elemento é particularmente relevante uma vez que existe grande discussão sobre a influência das reformas institucionais da década de 90 sobre mudança estrutural (Reinhardt e Peres, 2000) e incremento da produtividade (Ferreira e Rossi, 2003).

Tabela 1: Taxas de Crescimento do Valor Bruto da Produção, Valor da

Transformação Industrial, Pessoal Ocupado e Produtividade do Trabalho nas

Indústrias Brasileiras de Transformação e Extrativa em diversos períodos, 1970-2001 (\%)

\begin{tabular}{lcccccr}
\hline & & $1980 / 1970$ & $1985 / 1980$ & $1996 / 1985$ & $2001 / 1996$ & $2001 / 1970$ \\
\hline VBP & Total & 161,52 & $-11,43$ & 44,83 & 16,25 & 290,00 \\
\hline & a.a. & 10,09 & $-2,40$ & 3,42 & 3,06 & 4,49 \\
\hline VTI & Total & 139,02 & $-4,19$ & 50,46 & 8,50 & 273,85 \\
\hline & a.a. & 9,10 & $-0,85$ & 3,78 & 1,64 & 4,35 \\
\hline PO & Total & 99,81 & 11,85 & $-8,31$ & 5,87 & 116,93 \\
\hline & a.a. & 7,17 & 2,26 & $-0,79$ & 1,15 & 2,53 \\
\hline VTI/PO & Total & 19,62 & $-14,34$ & 64,11 & 2,48 & 72,33 \\
\hline & a.a. & 1,81 & $-3,05$ & 4,61 & 0,49 & 1,77 \\
\hline
\end{tabular}

Fonte: Elaboração própria a partir dos Censos Industriais de 1970, 1980 e 1985, das PIA de 1996 e 2001.

Dois argumentos costumam ser utilizados para explicar os efeitos da abertura comercial sobre a produtividade. O primeiro está associado ao incremento da participação de insumos estrangeiros na produção de mercadorias do país. O segundo tem referência na maior pressão competitiva sobre os produtores. Bonelli (2002), a partir de dados setoriais, não encontra evidência para comprovar a relação entre incremento da produtividade do trabalho e aumento do coeficiente de importação. Ferreira e Rossi (2003) encontram, utilizando micro-dados da PIA, que a redução de tarifas no período de 1988 a 1990 implicou em um ganho 
médio de cerca de $6 \%$ na produtividade total dos fatores. Muendler (2002) encontra correlação positiva entre o aumento da produtividade total dos fatores e dois outros elementos: o incremento da competição externa e o fechamento de empresas, ainda que o aumento no coeficiente de insumos - na mesma linha de Bonelli (2002) - não represente efeito positivo sobre a produtividade. Schor (2003) aponta que o nível de produtividade da produtividade total dos fatores é afetado positivamente pela redução de tarifas de produtos e de insumos das empresas, ainda que ressalte que a resposta possa vir a ser heterogênea, dependendo do setor de atuação e do tamanho da empresa.

Os resultados aqui encontrados não permitem relacionar a variação da produtividade a causas específicas. Contudo, embora após 1985 haja momentos de elevado crescimento da produtividade, a reversão da tendência à queda da produtividade, corretamente identificada por Bonelli (2002), independente da causa, não parece ter tido efeitos de longo prazo, tendo perdido seu fôlego a partir de 1996.

\subsection{Produtividade e Mudança Estrutural}

Um terceiro possível efeito da abertura comercial sobre a produtividade são as transformações estruturais. A abertura comercial ao alterar o vetor de preços relativos influenciaria o movimento inter-setorial de recursos, que migrariam de segmentos de baixa produtividade relativa para outros de elevada produtividade relativa (Timmer e Szirmai, 2000).

A tabela 2 apresenta a análise shift-share descrita na seção 2.1. A análise do período integral de 1970 a 2001 revela que o componente de eficiência intra-setorial explica $121 \%$ do crescimento da produtividade, ou seja, a soma do efeito composição com o efeito especialização dinâmica tem contribuição negativa no período. Quando os dois efeitos são analisados em separado, verifica-se a ocorrência de sinais invertidos entre os efeitos. Enquanto o efeito composição contribuiu em quase $85 \%$ para o crescimento da produtividade - contribuição próxima ao do efeito eficiência - o efeito especialização contribuiu negativamente para o crescimento da produtividade.

O efeito composição sugere que o emprego da economia cresceu na direção de setores de produtividade inicial (em 1970) maior. Os oito setores de maior produtividade inicial incrementaram sua participação no pessoal ocupado em 4,6 pontos percentuais, resultando em um incremento de 1,04 milhão de postos de trabalho entre 1970 e 2001. O sinal do efeito especialização dinâmica indica que o emprego da economia cresceu na direção de setores com menor taxa de crescimento da produtividade.

Os resultados em cada um dos sub-períodos não são homogêneos. No período entre 1970 e 1980, em que a produtividade da indústria cresce a uma taxa de $1,81 \%$ a.a., o efeito eficiência intra-setorial é o grande responsável pelo desempenho positivo, correspondendo a $132 \%$ do crescimento da produtividade e isoladamente significando um crescimento da produtividade de 2,34\% a.a., ou seja, caso a indústria tivesse mantido a mesma composição setorial do início do 
período, o crescimento da produtividade teria sido substancialmente maior. O bônus estrutural - representado pela soma do efeito composição com especialização dinâmica - é negativo. Nesse caso, os dois efeitos de conteúdo estrutural apresentam sinal negativo.

Tabela 2: Distribuição do Crescimento da Produtividade do Trabalho entre os Efeitos Eficiência, Estrutural e Adaptação Dinâmica, nas indústrias brasileiras de transformação e extrativa, em diversos períodos

\begin{tabular}{|c|c|c|c|c|c|c|}
\hline Efeito & & $\begin{array}{c}1970 \\
\text { a } 1980\end{array}$ & $\begin{array}{c}1980 \\
\text { a } 1985\end{array}$ & $\begin{array}{c}1985 \\
\text { a } 1996\end{array}$ & $\begin{array}{c}1996 \\
\text { a } 2001\end{array}$ & $\begin{array}{c}1970 \\
\text { a } 2001\end{array}$ \\
\hline & Total & 25,98 & $-17,78$ & 57,59 & 11,91 & 88,19 \\
\hline & $\%$ & 132,41 & 123,96 & 89,83 & 479,70 & 121,91 \\
\hline \multirow[t]{3}{*}{ Eficiência Intra-social } & a.a. & 2,34 & $-3,84$ & 4,22 & 2,28 & 2,06 \\
\hline & Total & $-3,36$ & 7,90 & 6,04 & $-4,08$ & 61,30 \\
\hline & $\%$ & $-17,10$ & $-55,05$ & 9,43 & $-164,26$ & 84,75 \\
\hline \multirow[t]{3}{*}{ Composição } & a.a. & $-0,34$ & 1,53 & 0,53 & $-0,83$ & 1,55 \\
\hline & Total & $-3,00$ & $-4,46$ & 0,48 & $-5,35$ & $-77,15$ \\
\hline & $\%$ & $-15,30$ & 31,09 & 0,74 & $-215,44$ & $-106,66$ \\
\hline \multirow[t]{3}{*}{ Especialização Dinâmica } & a.a. & $-0,30$ & $-0,91$ & 0,04 & $-1,09$ & $-4,65$ \\
\hline & Total & 19,62 & $-14,34$ & 64,11 & 2,48 & 72,33 \\
\hline & $\%$ & 100,00 & 100,00 & 100,00 & 100,00 & 100,00 \\
\hline Total & a.a. & 1,81 & $-3,05$ & 4,61 & 0,49 & 1,77 \\
\hline
\end{tabular}

Fonte: Elaboração própria a partir dos Censos Industriais de 1970, 1980 e 1985, e das PIA de 1996 e 2001.

No período de 1980 a 1985 , em que a produtividade decresce a uma taxa de $3,05 \%$ a.a., a eficiência intra-setorial tem resultado negativo, contribuindo em $123,96 \%$ para a redução da produtividade. O bônus estrutural é, portanto, positivo. Isso ocorre em razão do efeito composição que contribui em cerca de $55 \%$ para aumentar a produtividade, enquanto o efeito especialização dinâmica assume sinal negativo, contribuindo em $31 \%$ para o decréscimo da produtividade.

O período entre 1985 e 1996 se caracteriza como o único momento em que os efeitos intra-setorial e estrutural apresentam o mesmo sinal. Parece, portanto, não ser coincidência que seja o período de maior crescimento da produtividade: $4,61 \%$ a.a. O efeito eficiência é responsável por quase $90 \%$ do crescimento da produtividade, enquanto o efeito composição é responsável por quase $10 \%$. O efeito especialização dinâmica, ainda que positivo, é irrisório. Não é irrelevante estar alerta de que o período apresenta fases bastante heterogêneas, ${ }^{10}$ contendo

\footnotetext{
${ }^{10}$ Conforme colocado na metodologia, a impossibilidade de encontrar, em 1990, um ponto que separasse os dois períodos acarreta, certamente, prejuízo.
} 
uma fase com economia fechada e alta inflação, e outra com economia aberta e preços estabilizados.

No período que vai de 1996 a 2001, o efeito eficiência intra-setorial apresenta uma taxa de crescimento da produtividade de cerca de $2,28 \%$ a.a., semelhante àquela apresentada no período de 1970 a 1980. O resultado medíocre do crescimento da produtividade parece ser, portanto, conseqüência de uma mudança estrutural negativa. Deve ser enfatizado, então, que a trajetória de decréscimo da taxa de crescimento da produtividade identificada para o período 1996 a 2001, ainda que possa ter influência do decréscimo da taxa de ganho de eficiência da economia, é marcada pela inversão do sinal da mudança estrutural.

Uma das observações mais consistentes da tabela 2 parece ser o insistente sinal negativo do efeito especialização dinâmica. Apenas no período de 1985 a 1996, esse efeito não é negativo. A tabela 3 divide os setores em quatro categorias de acordo com a taxa de crescimento da produtividade e apresenta a participação de cada grupo de setores para a criação de novos postos de trabalho. Ao longo de todo o período, em maior parte dos postos de trabalho é criada em setores que pouco cresceram a produtividade. Em todos os períodos, os setores de alto crescimento da produtividade contribuem para a criação de postos de trabalho menos do que proporcionalmente a sua participação inicial no total de postos de trabalho. Com a exceção do período de 1985 a 1996, os setores de baixa e média-baixa taxa de crescimento da produtividade têm uma razão entre a contribuição para o crescimento dos postos de trabalho, e a participação inicial nos postos de trabalho superior aos setores de média-alta e alta taxa de crescimento da produtividade. Esses dados corroboram a descrição apresentada na tabela 2. A criação de empregos parece se concentrar nos setores de mais baixo crescimento da produtividade. Em segundo lugar, parece existir um aprofundamento dessa tendência. Os setores de alto crescimento da produtividade em cada sub-período apresentam, ao longo do tempo, contribuição cada vez menor para criação de novos postos de trabalho, sendo que, a partir de 1985, a contribuição é negativa, ou seja, os setores destroem postos de trabalho. 
Tabela 3: Participação dos Setores, de Acordo com Nível de

Crescimento da Produtividade do Trabalho, na Criação de Postos de Trabalho nas indústrias brasileiras de transformação e extrativa, em vários períodos, 1970-2001 (\%)

\begin{tabular}{|c|c|c|c|c|c|}
\hline \multirow[b]{2}{*}{ Dados } & \multicolumn{5}{|c|}{$\begin{array}{l}\text { Distribuição dos Setores por Categoria } \\
\text { de Acordo com a Taxa de Crescimento } \\
\text { da Produtividade em Cada Período }\end{array}$} \\
\hline & Baixo & $\begin{array}{c}\text { Médio } \\
\text { Baixo }\end{array}$ & $\begin{array}{l}\text { Médio } \\
\text { Alto }\end{array}$ & Alto & $\begin{array}{l}\text { Total } \\
\text { geral }\end{array}$ \\
\hline Participação PO 1970 & 24,45 & 24,80 & 28,53 & 22,22 & 100,00 \\
\hline Contribuição para Crescimento da PO 70 a 80 & 28,87 & 29,84 & 23,44 & 17,85 & 100,00 \\
\hline Contribuição/Participação & 1,18 & 1,20 & 0,82 & 0,80 & 1,00 \\
\hline Média Aritmética do Crescimento da Produtividade & $-16,80$ & 24,62 & 67,85 & 167,35 & 56,81 \\
\hline Participação PO 1980 & 12,12 & 28,02 & 38,23 & 21,63 & 100,00 \\
\hline Contribuição para Crescimento da PO 80 a 85 & 30,51 & 28,95 & 36,08 & 4,46 & 100,00 \\
\hline Contribuição/Participação & 2,52 & 1,03 & 0,94 & 0,21 & 1,00 \\
\hline Média Aritmética do Crescimento da Produtividade & $-48,19$ & $-30,26$ & $-15,74$ & 81,35 & $-6,35$ \\
\hline Participação PO 1985 & 19,62 & 25,80 & 36,67 & 17,91 & 100,00 \\
\hline Contribuição para Crescimento da PO 85 a 96 & 34,30 & $-1,95$ & 75,13 & $-7,48$ & 100,00 \\
\hline Contribuição/Participação & 1,75 & $-0,08$ & 2,05 & $-0,42$ & 1,00 \\
\hline Média Aritmética do Crescimento da Produtividade & $-4,10$ & 44,21 & 82,32 & 394,83 & 119,48 \\
\hline Participação PO 1996 & 15,32 & 48,24 & 28,99 & 7,45 & 100,00 \\
\hline Contribuição para Crescimento da PO 96 a 01 & 21,67 & 94,48 & 10,36 & $-26,51$ & 100,00 \\
\hline Contribuição/Participação & 1,41 & 1,96 & 0,36 & $-3,56$ & 1,00 \\
\hline Média Aritmética do Crescimento da Produtividade & $-23,12$ & $-2,79$ & 19,10 & 135,61 & 28,37 \\
\hline
\end{tabular}

Fonte: Elaboração própria a partir do Censo Industrial 1970, 1980 e 1985 e da PIA 1996 e 2001.

\subsection{Produtividade e Emprego}

Existem distintas interpretações a respeito da relação entre crescimento da produtividade e emprego. Essa seção explorará duas interpretações específicas, não necessariamente excludentes:

1. Possível baixa elasticidade do emprego em relação à produtividade (Fagerberg, 2000; e

2. Problemas associados à mudança da composição do emprego na economia, na direção de setores de menor crescimento da produtividade (Baumol, 1967). ${ }^{11}$

\footnotetext{
${ }^{11}$ Uma terceira interpretação associada à queda da proporção de gastos em $\mathrm{P} \& \mathrm{D}$ com relação ao produto é explorada por Griliches (1980)
} 
A primeira justificativa está associada aos argumentos de Fagerberg (2000) sobre mudanças na direção do progresso técnico que, ao longo tempo, teria se deslocado para setores que são pouco criadores de emprego; ou seja, a elasticidade do emprego em relação à produtividade teria se reduzido. Em exame crosssection para 39 países, Fagerberg (2000) apresenta resultados semelhantes. Em apenas seis países, o efeito não assume sinal negativo, mas seu impacto é desprezível. Para entender melhor esse resultado, Fagerberg (2000) elabora uma regressão que relaciona crescimento do valor adicionado com crescimento do emprego para dois momentos diferentes ${ }^{12}$ calculando a elasticidade do emprego com respeito à produtividade. Encontra que a elasticidade se reduz no tempo, o que de acordo com o autor indicaria que:

“(...) no período anterior, indústrias caracterizadas por rápida mudança tecnológica também incrementavam sua participação na produção e no emprego a taxas rápidas. (...) Contudo, as indústrias líderes tecnológicas no atual período de estudo, isto é, eletrônica, não estão associadas a mudanças na estrutura da demanda na mesma extensão (...)" [Fagerberg (2000:404-5)].

A tabela 4 apresenta a estimativa para o Brasil das regressões rodadas por Fagerberg (2000). A variável dependente é a variação do emprego no período e a variável independente é a variação do valor da transformação industrial. ${ }^{13} \mathrm{~A}$ semelhança de Fagerberg (2000), parece haver, ao longo do tempo uma redução da elasticidade do emprego com relação à produtividade. ${ }^{14}$ Deve-se enfatizar que, no período de maior crescimento da produtividade, de 1985 a 1996, o coeficiente da regressão do valor adicionado em relação ao emprego nem mesmo é significativo estatisticamente.

Os resultados parecem sugerir, portanto, um descolamento da série de crescimento do valor da transformação industrial em relação à série de emprego. Parece existir uma radicalização das conclusões de Ferraz et al. (2004) que apontam para um crescimento do valor da transformação industrial e um decréscimo do emprego. Os resultados apresentados sugerem que esse descolamento é acompanhado por um aprofundamento da heterogeneidade produtiva ${ }^{15}$ ao mostrar

\footnotetext{
${ }^{12}$ A amostra de Salter (1960) associada ao período de 1924 a 1950 é contrastada com a amostra de Fagerberg (2000) para o período de 1973 a 1990.

${ }^{13}$ Supondo $\eta=\alpha+b y$ em que $\eta$ é a taxa de crescimento do emprego e $y$ seja a taxa de crescimento do valor adicionado, a taxa de crescimento da produtividade representada por $(y-n)$ é obtida por algumas operações algébricas, tal que $n=\frac{a}{1-b}+\frac{b}{1-b}[y-n]$, em que $\frac{b}{1-b}$ é a elasticidade do emprego em relação à produtividade.

${ }^{14}$ Conforme pode ser visto, a súbita queda referente ao período de 1985 a 1996 não deve ser levada em consideração, dado o sinal da variável VTI não ser significativo.

${ }^{15}$ Dois trabalhos apresentam relato com respeito ao aprofundamento da heterogeneidade produtiva: Rocha (2004), Carvalheiro (2003) e Kupfer e Rocha (2004).
} 
que os setores em que mais cresce a produtividade criam muito pouco ou nenhum emprego.

A segunda interpretação para a relação frágil entre emprego e produtividade é fornecida por Baumol (1967) e pode auxiliar na compreensão da dinâmica sugerida pelos resultados da regressão da tabela 4 . O modelo é elaborado a partir da existência de dois setores: um progressivo, de alto crescimento da produtividade, e outro estagnado, de baixo crescimento da produtividade. A composição da demanda é estável e existe livre mobilidade de fatores e livre concorrência. O setor progressivo determina, por intermédio de sua produtividade, o salário, que também deve ser pago no setor estagnado. Assim, com o crescimento da produtividade, há demissões da mão-de-obra do setor progressivo que é realocada no setor estagnado. Como o salário deve ser pago em termos de produtividade marginal do setor progressivo, há aumento dos preços do setor estagnado em relação ao setor progressivo. Como conseqüência:

1. A mão-de-obra se acumula no setor estagnado;

2. A participação dos setores na economia se mantém constante ao longo do tempo, quando o valor adicionado é medido a preços constantes;

3. Há aumento da participação do setor estagnado e redução do setor progressivo no valor adicionado, quando medido a preços correntes.

Tabela 4: Regressão Variação do Valor da Transformação

Industrial contra Variação do Pessoal Ocupado

\begin{tabular}{ccccc}
\hline & \multicolumn{2}{c}{ Regressão } & & $\begin{array}{c}\text { Elasticidade do Emprego } \\
\text { com Relação } \\
\text { à Produtividade }\end{array}$ \\
\hline $1970-80$ & $1,13^{*}$ & $0,28^{*}$ & 0,666 & 0,39 \\
\hline $1980-85$ & $1,10^{*}$ & $0,21+$ & 0,086 & 0,26 \\
\hline $1985-96$ & $0,90^{*}$ & 0,03 & 0,057 & 0,03 \\
\hline $1996-01$ & $0,89^{*}$ & $0,13^{*}$ & 0,671 & 0,15 \\
\hline
\end{tabular}

* Significativo a $1 \%$

+ Significativo a $10 \%$.

O teste dessa interpretação é realizado a partir da divisão dos setores em quatro grupos, de acordo com a taxa de crescimento da produtividade: alto crescimento da produtividade, médio-alto crescimento da produtividade, médio-baixo crescimento da produtividade e baixo crescimento da produtividade. ${ }^{16} \mathrm{~A}$ par-

\footnotetext{
${ }^{16}$ A distribuição dos setores, de acordo com essa classificação, é apresentada no anexo 2. Note-se também que a referência para a distribuição dos setores entre taxas de crescimento da produtividade, nos gráficos 1 e 2, é o período como um todo, de 1970 e 2001, enquanto na tabela 3a divisão se refere ao crescimento da produtividade em cada sub-período (entre 1970 e 1980, 1980 e 1985, 1985 e 1996, e 1996 e 2001).
} 
tir dessa divisão, acompanhou-se a participação de cada grupo de setores no produto a preços constantes e a preços correntes, ao longo do período analisado. Os resultados são apresentados no gráfico 1. Alguns elementos podem ser destacados a partir de sua observação. Inicialmente, ao contrário da hipótese formulada pelo modelo de Baumol (1967), a composição da demanda final se altera ao longo do tempo, com os setores de maior crescimento da produtividade aumentando sua participação no valor da transformação industrial ao longo do período, enquanto os segmentos de menor crescimento da produtividade perdem sua participação ao longo do mesmo período.

Gráfico 1: Evolução da Participação no Valor da Transformação Industrial dos Setores Agrupados de Acordo com a Taxa de Crescimento da Produtividade do Trabalho entre 1970 e 2001, Indústrias Brasileiras Extrativa e de Transformação, (\%)
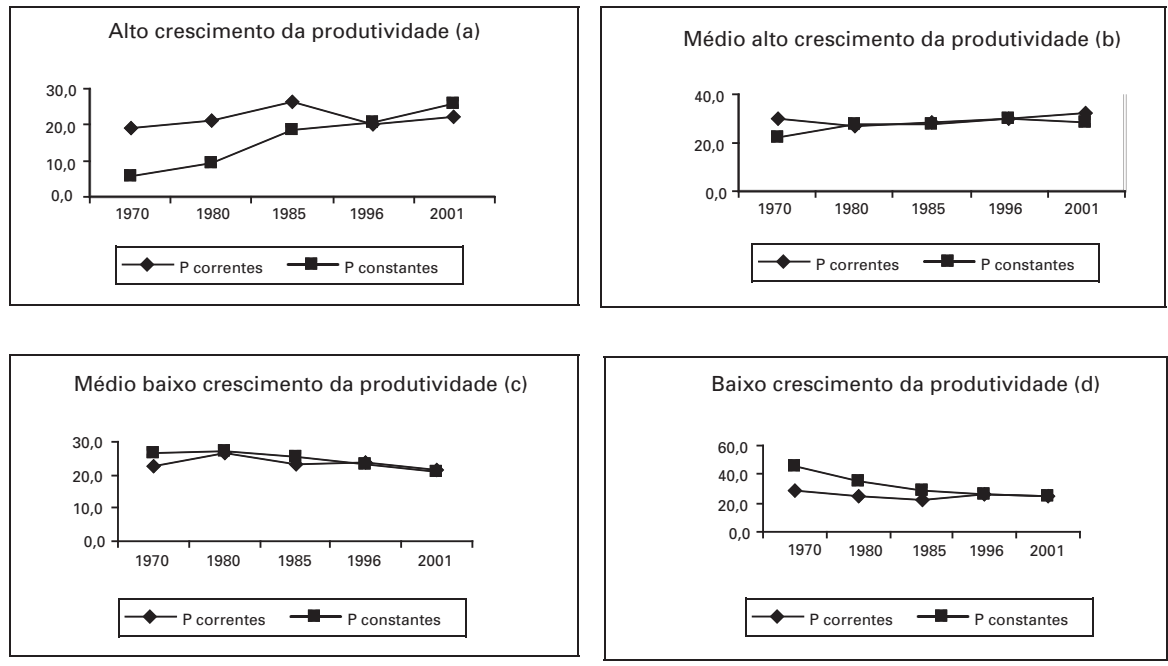

Fonte: Elaboração própria a partir dos Censos Industriais de 1970, 1980 e 1985 e das PIA de 1996 e 2001. Preços constantes de agosto de 1994.

Quando os quatro grupos de setores são examinados isoladamente, percebese que a participação dos setores de médio-alto e médio-baixo crescimento da produtividade no valor da transformação industrial a preços constantes e a preços correntes seguem trajetórias semelhantes. No caso dos setores de alto crescimento da produtividade, existe uma tendência à estabilidade de sua participação no valor da transformação industrial a preços correntes e, conforme denotado, um crescimento a preços constantes, sugerindo a confirmação da hipótese de Baumol de que a produtividade é repassada mediante preços. Conforme também previsto, o processo inverso é verificado nos setores de baixo crescimento da produtividade.

Contudo, quando é examinada a distribuição do emprego entre os tipos de setores, conforme apresentado no gráfico 2, percebe-se que o mesmo desempenho apresentado em relação à demanda não é acompanhado no que se refere ao emprego: 
1. Os setores de alto crescimento da produtividade ganham participação no emprego até 1985, estabilizando-se posteriormente;

2. Os setores de médio-alto crescimento da produtividade perdem participação ao longo dos anos;

3. Os setores de médio-baixo crescimento da produtividade crescem ligeiramente sua participação até 1985 , caindo a partir de então; e

4. Os setores de baixo crescimento da produtividade perdem participação até 1985, mas ganham rapidamente a partir de então.

Gráfico 2: Distribuição do Emprego da Indústria Extrativa e de Transformação entre os Setores Classificados de Acordo com a Taxa de Crescimento da Produtividade do Trabalho no Brasil, (\%)

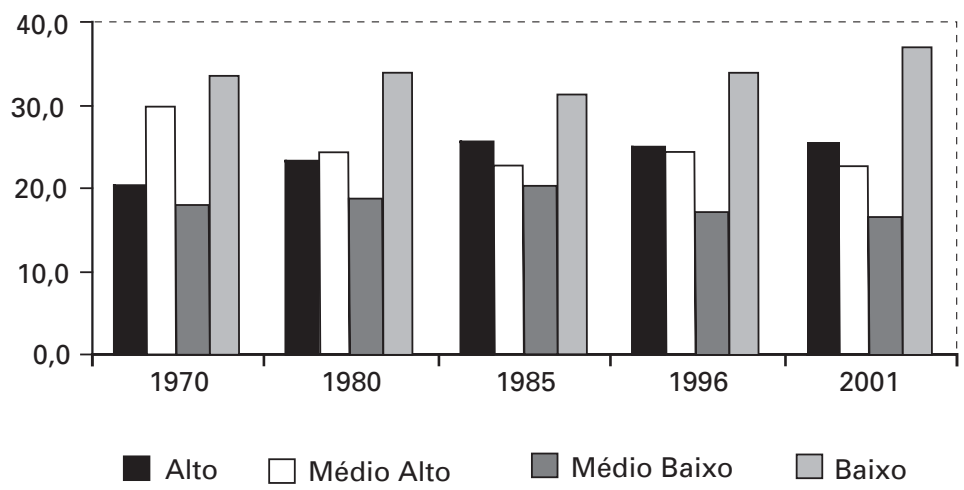

Fonte: Elaboração própria a partir dos Censos Industriais 1970, 1980 e 1985 e das PIA de 1996 e 2001.

As observações levantadas sugerem haver uma mudança na trajetória do emprego entre os setores industriais. Até 1985, os setores de maior crescimento da produtividade ganham participação em detrimento dos segmentos de alto-médio crescimento da produtividade; a partir de 1985, os setores que menos cresceram sua produtividade no período passam a ganhar participação na mão-de-obra, em detrimento dos setores de médio-alto e médio-baixo crescimento da produtividade.

\section{CONCLUSÕES}

O trabalho realizou uma análise shift-share para mensurar os efeitos da mudança estrutural sofridas pela indústria extrativa e de transformação em diversos sub-períodos entre 1970-2001 sobre a variação de sua produtividade. Para tanto, usou um indicador de produtividade do trabalho. A divisão das três décadas analisadas em sub-períodos, além de ter procurado espelhar fases distintas teve sua 
distribuição limitada pela disponibilidade de bases de dados. Portanto, esforços adicionais que ampliem o uso de indicadores alternativos e permitam a melhor visualização dos sub-períodos analisados são bem vindos.

O trabalho levanta dúvidas sobre a permanência de uma trajetória de crescimento da produtividade após um breve período de transição a partir de finais da década de 80 . Nesse caso, os dados aqui levantados sobre produtividade do trabalho contrastam com aqueles levantados por Bonelli (2002) para produtividade física do trabalho. Conforme apresentado, a partir de meados da década de 90 , há uma redução no ritmo de crescimento da produtividade. Ainda que os resultados não permitam associar diretamente a variação da produtividade a mudanças institucionais, eles sugerem que as mudanças ocorridas na abertura comercial não são condição suficiente para uma mudança de trajetória duradoura.

Não se pode identificar a ocorrência de bônus estrutural no período analisado. Ao contrário, a mudança estrutural parece ter contribuído negativamente para o crescimento da produtividade. Apenas nos períodos intermediários de 1980 a 1985 e de 1985 a 1996, a mudança estrutural contribui positivamente para o crescimento da produtividade. Mesmo assim, a contribuição é pequena. Nos demais períodos, sua contribuição é negativa. Quando a mudança estrutural é decomposta em dois efeitos (composição e especialização dinâmica), pode-se perceber que o efeito composição apresenta eventualmente sinal positivo, enquanto o efeito especialização dinâmica é negativo em três dos quatro períodos analisados, sugerindo uma especialização crescente da indústria nos segmentos em que a produtividade cresce mais lentamente. Ênfase especial deve ser dada ao fato de esse efeito ser particularmente mais forte no último sub-período analisado, ou seja, entre 1996 e 2001. O manuseio dos dados mostrou que, de fato, os setores de menor crescimento da produtividade são os que apresentaram maior contribuição para a criação de postos de trabalho. Acrescenta-se que, a partir de 1985, os setores de baixo crescimento da produtividade incrementam substancialmente sua participação no emprego. Dada a limitação da metodologia, não é possível analisar a causalidade entre os fenômenos. O trabalho indica, contudo, que maior esforço deve ser dirigido para o exame da causalidade entre crescimento do emprego e baixo crescimento da produtividade, e sua possível relação com alguma doença de custos.

\section{REFERÊNCIAS BIBLIOGRÁFICAS}

BAUMOL W. (1967) "Macroeconomics of Unbalanced Growth: The Anatomy of an Urban Crisis". The American Economic Review, June.

BONELLI, R. (2002) “Labor Productivity in Brazil during the 90's”. IPEA, Texto para discussão, n. 906, Rio de Janeiro.

CHENERY, H. (1986) “Growth and Transformation”. In: Chenery, H.; Robinson, S. e Syrquin, M. Industrialization and Growth. Oxford: Oxford University Press.

CARVALHEIRO, N. (2003) "Uma decomposição do aumento da produtividade do trabalho no Brasil durante os anos 90". Revista de Economia Contemporânea, 7(1): 81-109. 
CHENERY, H.; ROBINSON, S. e SYRQUIN, M. (1986) Industrialization and Growth. Oxford: Oxford University Press.

COUTINHO, L. (1997) A especialização regressiva: um balanço do desempenho industrial pósestabilização In: Veloso, J. P. Brasil: desafios de um país em transformação, Rio de Janeiro: José Olympio.

FAGERBERG, J. (2000) “Technological progress, structural change and productivity growth: a comparative study”. Structural Change and Economic Dynamics, 11: 393-411.

FERRAZ, J. C.; KUPFER, D. e IOOTTY, M. (2004) “Competitividad Industrial en Brasil: 10 años después de la liberalización”. Revista de la Cepal, 92: 91-119.

FERREIRA, P. e ROSSI, J. (2003) New Evidence from Brazil on Trade Liberalization and Productivity Growth. International Economic Review, 44(4): 1383-1405.

GRILICHES, Z. (1980) R\&D and the Productivity Slowdown. The American Economic Review, 70: 343-348, maio.

HARBERGER, A. (1998) A vision of the growth process. The American Economic Review, $88(1): 1-32$.

KATZ, J. (2000) Structural Change and Labor Productivity Growth in Latin American Manufacturing Industries, 1970-96, World Development, 28 (9): 1583-1596.

KUSNETZ, S. (1973) "Modern economic growth: findings and reflections". The American Economic Review, 63: 247-258.

MUENDLER, M. A. (2004) "Trade technology and productivity: a study of Brazilian manufacturers 1986-1998”. CESifo Working Paper Series No. 1148, http://papers.ssrn.com/sol3/papers.cfm?abstract_id=525924.

OCDE Measuring Productivity, OECD Manual, Measurement of Aggregate and Industry Level Productivity Growth. http://www.oecd.org, 2001.

REINHARDT, N. e PERES, W. (2000) “Latin America's new economic model: micro responses and economic restructuring”, World Development, 28 (9): 1543-1563.

ROCHA, F. e KUPFER, D. (2002) "Structural changes and specialization in Brazilian industry: the evolution of leading companies and the M\&A process". The Developing Economies, vol. XL, 4: 497-521.

ROCHA, F. (2004) "Heterogeneidade estrutural, composição setorial e tamanho da empresa nos anos 1990". Economia e Sociedade 13(1): 61-76.

SCHOR, A. (2003) Productivity: Competition, Embodied Technology and Heterogeneous Response to Tariff Reduction. Evidence from Brazilian Manufacturing Industries. NBER Working Paper No. W10544, http://papers.ssrn.com/sol3/papers.cfm?abstract_id=556531, June.

SYRQUIN, M. (1988) "Patterns of Structural Change”. In: Chenery, H. E Srinivasan, T. Handbook of Development Economics. Elsevier.

SYRQUIN, M. (1986) "Productivity Growth and Factor Allocation”. In: Chenery, H., Robinson, S. E Syrquin, M. Industrialization and Growth. Oxford: Oxford University Press.

TIMMER, M. e SZIRMAI, A. (2000) "Productivity Growth in Asian Manufacturing: the structural bonus hypothesis examined". Structural Change and Economic Dynamics, 11: 371392.

WOLFF, E. (1985) "Industrial composition, interindustry effects and the US productivity slowdown". The Review of Economics and Statistics, 67(2): 268-277. 
ANEXOS

Anexo 1: Compatibilização da Classificação

\begin{tabular}{|c|c|c|c|}
\hline \multirow{2}{*}{$\begin{array}{l}\text { Censo } \\
\text { Extração de Minerais }\end{array}$} & \multirow[t]{2}{*}{ Desagregação } & \multirow{2}{*}{$\begin{array}{c}\text { CNAE } \\
\text { Seção C }\end{array}$} & \multirow{2}{*}{$\frac{F G V}{28}$} \\
\hline & & & \\
\hline \multicolumn{2}{|c|}{ Transformação de Minerais Não-Metálicos } & 26 & 30 \\
\hline \multicolumn{2}{|l|}{ Metalurgia } & $27+28$ & 32 \\
\hline \multicolumn{2}{|l|}{ Mecânica } & 29 & 36 \\
\hline \multirow[t]{3}{*}{ Material Elétrico e Comunicações } & Material Elétrico & 31 & 38 \\
\hline & Eletrônico & 30 & 38 \\
\hline & Comunicações & 32 & 38 \\
\hline \multirow[t]{3}{*}{ Material de Transporte } & Automóveis, Caminhões e Auto-peças & 34 & 43 \\
\hline & Outros Transportes & $35-353$ & 44 \\
\hline & Construção e Montagem de Aviões & 353 & 44 \\
\hline \multicolumn{2}{|l|}{ Madeira } & 20 & 45 \\
\hline \multicolumn{2}{|l|}{ Mobiliário } & 361 & 46 \\
\hline \multicolumn{2}{|l|}{ Papel e Papelão } & 21 & 50 \\
\hline \multicolumn{2}{|l|}{ Borracha } & 251 & 51 \\
\hline \multicolumn{2}{|l|}{ Couros e Peles } & 19-193 & 52 \\
\hline \multirow[t]{2}{*}{ Química } & $\begin{array}{l}\text { Química menos Fabricação de produtos } \\
\text { Químicos Derivados do } \\
\text { Processamento do Petróleo, de } \\
\text { Rochas Oleagenosas, do Carvão } \\
\text { Mineral e do Álcool }\end{array}$ & $24-245-247$ & 53 \\
\hline & $\begin{array}{l}\text { Fabricação de produtos Químicos } \\
\text { Derivados do Processamento do } \\
\text { Petróleo, de Rochas Oleagenosas, } \\
\text { do Carvão Mineral e do Álcool }\end{array}$ & 23 & 54 \\
\hline \multicolumn{2}{|c|}{ Produtos Farmacêuticos e Veterinários } & 245 & 81 \\
\hline \multicolumn{2}{|l|}{ Perfumaria, Sabões e Velas } & 247 & 82 \\
\hline \multicolumn{2}{|l|}{ Produtos de Matérias Plásticas } & 252 & 83 \\
\hline \multicolumn{2}{|l|}{ Têxtil } & 17 & 60 \\
\hline \multicolumn{2}{|c|}{ Vestuário, Calçados e Artefatos de Tecidos } & $18+193$ & 64 \\
\hline \multicolumn{2}{|l|}{ Produtos Alimentares } & $15-159$ & 70 \\
\hline \multicolumn{2}{|l|}{ Bebidas } & 159 & 66 \\
\hline \multicolumn{2}{|l|}{ Fumo } & 16 & 69 \\
\hline \multicolumn{2}{|l|}{ Editorial e Gráfica } & 22 & 50 \\
\hline \multicolumn{2}{|l|}{ Diversos } & $33+369$ & 29 \\
\hline
\end{tabular}


Anexo 2: Distribuição dos Setores de Acordo com a Taxa de Crescimento da Produtividade, no período 1970-2001

\begin{tabular}{c|c}
\hline Alto Crescimento da Produtividade & Médio Baixo Crescimento da Produtividade \\
\hline Construção e Montagem de Aviões & Fumo \\
\hline Material Eletrônico & Bebânica \\
\hline Material de Comunicação & Diversos \\
\hline Extração de minerais & Química \\
\hline Vestuário, calçados e artefatos de tecido & Borracha \\
\hline Metalurgia & Perfumarias, Sabões e velas \\
\hline Médio-Alto Crescimento da Produtividade & Baixo Crescimento da Produtividade \\
\hline Material elétrico & Produtos de minerais não-metálicos \\
\hline Têxtil & Mobiliário \\
\hline Automóveis, Caminhões e Auto-peças & Produtos alimentares \\
\hline Papel e Papelão & Produtos de materiais plásticos \\
\hline Outros Transportes & Produtos farmacêuticos e veterinários \\
\hline Combustíveis e Lubrificantes & Madeira \\
\hline Editorial e gráfica & Couro e peles \\
\hline
\end{tabular}

